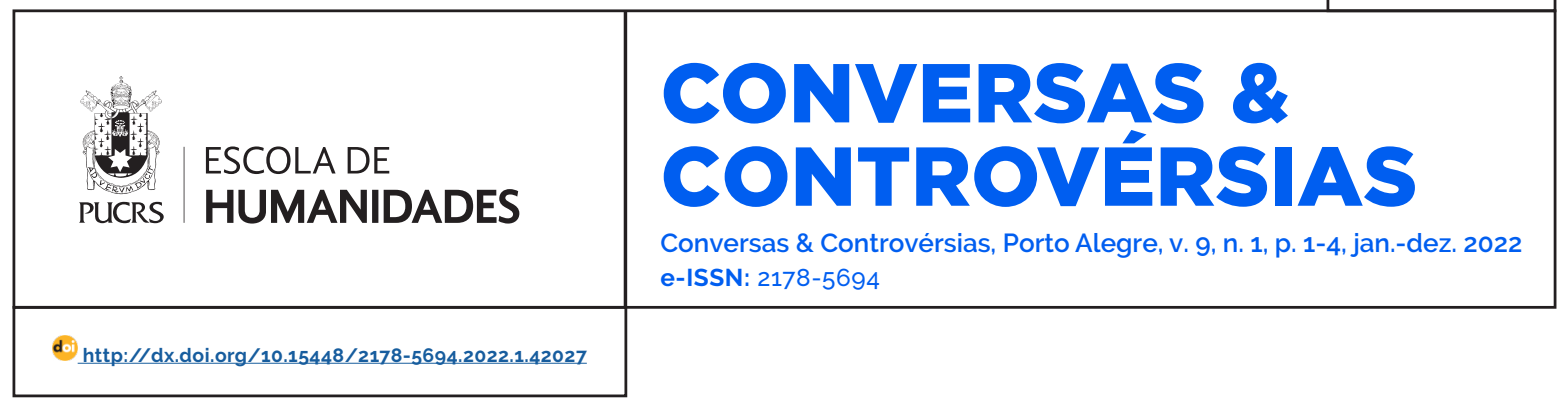

SEÇÃO: RESENHA

\title{
"A China Venceu? O Desafio Chinês à Supremacia Norte- Americana", de Kishore Mahbubani
}

\author{
"Has China Won? The Chinese Challenge to the American Primacy", from Kishore \\ Mahbubani
}

\author{
Vitor Piagetti Aimi ${ }^{1}$ \\ orcid.org/0000-0002-3237-0781 \\ vitor.aimi@acad.pucrs.br
}

Recebido em: 23/10/2021. Aprovado em: 23/10/2021. Publicado em: 04/02/2022.
Resumo: A presente resenha busca explicar as principais ideias presentes no Livro A China Venceu? O Desafio Chinês à Supremacia Norte-Americana. O autor, Kishore Mahbubani, é diplomata e acadêmico da Universidade Nacional de Singapura. Atuou como ministro das relações exteriores de Singapura por mais de três décadas e foi presidente do conselho de segurança das Nações Unidas na gestão 2001-2002. A análise de sua mais recente obra é pertinente pela experiência em importantes postos de estado e pela importância que esse conflito ocupa nas relações internacionais contemporâneas.

Palavras-chave: China. Estados Unidos. Geopolítica.

Abstract: The following review intends to present the main ideas presented in the book Has China Won? The Chinese Challange to American Primacy. The author, Kishore Mahbubani, is a diplomat and academic in the National University of Singapure. He hás acted as minister of foreign affairs of Singapure for more than three decades and was president of the security council of the United Nations in the 2001-2002 period. The analysis of his most recent work is important because of his experience in key positions of state and because of the importance this conflicts weights in the contemporary international relations.

Keywords: China. United Stated. Geopolitics.

Kishore Mahbubani é um influente pensador contemporâneo das Relações Internacionais. Cingapurense de origem indiana, ocupou importantes postos estratégicos no governo de Cingapura. Em sua mais recente obra, A China Venceu ? Desafio Chinês à Supremacia Norte-Americana, nos empresta sua privilegiada visão estratégica para que melhor possamos compreender o complexo cenário geopolítico que vem delineando-se ao longo das últimas décadas.

O sistema internacional, tal como conhecemos hoje, tem sua configuração político-econômica constituída a partir de eventos-chave ocorridos durante a década de 1970, notadamente o fim do sistema de Bretton Woods, vigente entre 1944 e 1971, e a primeira crise do petróleo, ocorrida em 1973. O desarranjo das regras monetárias internacionais junto ao encarecimento dos insumos energéticos em uma sociedade excessivamente dependente do petróleo fez com que o cenário da época fosse de taxas de câmbio voláteis e altos juros para frear a subida inflacionária. 
Concomitantemente, as rígidas regulações financeiras foram afrouxadas, e as barreiras que impediam a livre circulação dos fatores de produção entre países diminuídas. As inovações no campo das telecomunicações, a partir da década de 1980, concorreram para este cenário de maior intensidade no fluxo capital e humano. A estrutura do estado de bem-estar social nos paises industrializados e do estado desenvolvimentista nos países subdesenvolvidos começaria a ser desmontada, dando lugar a uma lógica de austeridade fiscal e contração monetária. O desfecho da Guerra Fria, em 1989 faria encerrar de vez o antigo sistema internacional vigente.

As consagradas obras O Fim da História, de Fukuyama (1992) e A Guerra de Civilizações, de Huntington (1996) ilustram este momento de tensão entre a esperança em um novo mundo e o medo da dissolução da velha ordem. Paralelamente a este processo, atores internacionais antes marginalizados começariam a ganhar protagonismo. No centro desse fenômeno esteve a China, que iniciava sua transição de país predominantemente rural a superpotência.

O país asiático, através de uma profunda reforma econômica, iniciada em 1978, criava as Zonas Econômicas Especiais (ZEE): "ilhas de capitalismo" em cidades litorâneas, que passariam a operar segundo a lógica do livre mercado. Tendo o baixo custo de mão de obra como principal atrativo, a China atraiu para o seu território estágios produtivos de empresas estrangeiras, sobretudo ocidentais e japonesas. Crescendo a taxas médias anuais de dois dígitos desde o início das reformas econômicas, o país tem reafirmado suas pretensões globais no século XXI através de intensos fluxos de investimento a paises em desenvolvimento, buscando obter não apenas insumos necessários à sua rápida industrialização, mas também influência política.

A expansão chinesa, entretanto, tem desagradado aqueles que possuem interesse em manter o status quo do poder global. Atores internacionais já consagrados mostram cada vez mais antipatia à ascensão do país oriental ao posto de superpotência. Dentre as nações descontentes com o cenário imposto pela China estão os Estados Unidos, potência hegemônica desde o fim da Segunda Guerra Mundial. A célebre "guerra comercial" imposta pelo então presidente republicano Donald Trump, em 2016, ilustra o estado de tensões que os dois paises vivem na contemporaneidade e o interesse americano em frear a ascensão chinesa, em um tentativa de preservar seu domínio global.

O resultado deste jogo de forças é ainda incerto, e embora ainda não seja possivel vislumbrar de modo claro a maneira em que acabará este embate cada vez mais aberto e explícito entre a velha e a nova ordem, dispomos cada vez mais de intelectuais que oferecem um diagnóstico de para onde estamos indo.

Enquanto autores consagrados, tais como Henry Nau (1990), em O Mito da Decadência dos Estados Unidos, advogam que a decadência norte-americana seja uma ilusão contemporânea digna de ficção, outros pensadores, tais como Jan Pieterse (2009), em O Fim do Império Americano, já decretam o fim da hegemonia do país.

Kishore Mahbubani (2020), por sua vez, investido de sua vasta experiência geopolítica, apresenta uma visão mais ponderada sobre o assunto. Nos nove capítulos do seu mais novo livro, intitulado A China Venceu ? O Desafio Chinês à Supremacia Norte-Americana, reconhece o assunto como complexo e intrincado, dando sugestões aos dois lados de como agir neste conflito contemporâneo.

O autor inicia a obra apontando as virtudes e os vícios do país americano, indicando que, se por um lado os Estados Unidos ainda possuem capital político para liderar o mundo, sua fragilidade é aparente. Dentre as qualidades norte-americanas destacadas por Mahbubani estão a excelência do país no âmbito acadêmico, a extraordinária capacidade da nação em produzir conhecimento e em cultivar grandes mentes, além da eminente predominância do dólar no sistema financeiro internacional.

Embora crítico do fenômeno do trumpismo no país do atlântico norte, o autor vê como importante o passo estratégico conquistado pelo ex-presidente na conscientização nacional da China como adversário que merece a atenção 
dos compatriotas. Isso teria permitido com que os Estados Unidos considerassem uma política de estado mais abrangente e coesa no tratamento com os chineses.

Não obstante o reconhecimento das virtudes estadunidenses, o autor destaca as falhas estratégicas dos Estados Unidos no século XXI. Dentre elas, a que mais custará à nação será a arrogância. O país crê ter mais aliados do que realmente tem, e, no momento de maior acirramento do embate entre as potências, os lideres americanos poderão amargurar-se ao descobrir que muitos daqueles que imaginam estar ao seu lado poderão escolher a China.

Outro famoso diplomata, Henry Kissinger, secretário de estado norte-americano na década de 1970, expõe a mesma opinião em Sobre a China. Segundo Kissinger (2011), os Estados Unidos pecam na falta de humildade ao promover conflitos com outros países ao invés de buscar cooperação internacional, tal como tem feito a China em seu caminho rumo a superpotência global.

O sistema eleitoral estadunidense, segundo Mahbubani, seria um dos motivos da dificuldade do pais em adquirir a realpolitik e inserir-se de modo estratégico nas relações internacionais. $\mathrm{O}$ sistema de votos não mais guardaria correspondência com o ideal da democracia propagada pelos pais fundadores da nação. O que há, ao invés, é uma cooptação política de uma elite que tem interesses escusos, sem pensar no bem geral da nação.

Enquanto os Estados Unidos têm dificuldade em formular uma política de estado que pense no bem comum do país, o Partido Comunista Chinês (PPC), por turno, tem apresentado exímia competência em dar voz aos anseios do nação e promover os interesses nacionais. Não apenas de influência interna vive o partido, no entanto. Através do modelo de crescimento para fora, a China tornou-se o quarto maior investidor do mundo. Acumulando reservas internacionais de mais de 3,2 trilhões de dólares, tem investido intensamente nos vizinhos asiáticos, na África e na América Latina, onde procura obter comodities para financiar sua industrialização.
O país já é o principal parceiro comercial da União Europeia e da África, e, rapidamente, torna-se o principal parceiro econômico de muitos países latinos. Este é o caso do Brasil, que tem a China como principal parceiro comercial desde 2009. O ocidente, para o ex-ministro, não é capaz de compreender o sucesso que o PCC vem experimentando, e isto decorreria devido à insistência do pensamento político ocidental em ver a democracia representativa como modelo universal e incontestável.

O autor lembra que o PCC tem cada vez maior aprovação no país ao retirar significativa parcela da população da situação de extrema pobreza, aumentando de modo rápido a qualidade de vida e o ritmo de urbanização. Ignorar a satisfação de 1,4 bilhões de cidadãos com seu governo é o mesmo que recusar-se a compreender a conjuntura política contemporânea, pondera o intelectual.

Mahbubani ainda sublinha que embora a democracia seja um regime político chancelado no ocidente, a Ásia tem sistematicamente mostrado a recusa desta forma de governo ao longo dos anos. Este regime político, aos olhos dos asiáticos, mais parece uma imposição externa que uma força política legítima. Aprender esta lição, além de um gesto de humildade, é fundamental caso o ocidente queira continuar sendo um player influente nas relações internacionais contemporâneas. A dificuldade em perceber a China além dos valores ocidentais é um dos motivos do insucesso dos Estados Unidos na formulação de políticas bem-sucedidas junto ao país asiático.

Não são apenas elogios, entretanto, que o pensador reserva ao país oriental. O cingapurense alerta para que a China não caia no mesmo erro dos Estados Unidos em resvalar na arrogância de julgar-se mais forte do que realmente é. Dentre os exemplos de que o país oriental tem mostrado persistência neste erro estratégico, o autor destaca a tendência nos últimos anos dos chineses em buscar conflito com outros países, quando poderia buscar resolução por outras vias. As crescentes trocas de hostilidades com Taiwan, além das manobras militares junto ao mar japonês mostram de maneira inequivoca a recente pre- 
ferência chinesa em preterir um plano de longo prazo em troca de pequenos ganhos imediatos.

A atitude cada vez mais agressiva de diplomatas chineses nas embaixadas estrangeiras também revela a prepotência que o país tem incorrido nos tempos recentes. Tais movimentos, embora resultem em ganho de popularidade doméstico, são extremamente mal recebidos pela comunidade internacional. $O$ autor ressalta que se os Estados Unidos nunca souberam ficar em segundo lugar, a China ainda não experimentou o que é estar em primeiro.

\section{Referências}

Fukuyama, Francis. 1992. O fim da história e o último homem. Rio de Janeiro: Rocco.

Huntington, Samuel P. 2010. O choque de civilizações e a recomposição da ordem mundial. Tradução de M. H. C. Côrtes. Rio de Janeiro: Objetiva.

Kissinger, Henry. 2011. Sobre a China. Rio de Janeiro: Objetiva.

Mahbubani, Kishore. 2021. A China Venceu? O Desafio Chinês à Supremacia Norte-Americana. Rio de Janeiro: Intrinseca.

Nau, Henry. 2003. O mito da decadência dos Estados Unidos. Rio de Janeiro: Jorge Zahar.

Pieterse, Jan. 2009. O Fim do Império Americano? Rio de Janeiro: Forense Universitária.

\section{Vitor Piagetti Aimi}

Graduando em Ciências Sociais pela Pontifícia Universidade Católica do Rio Grande do Sul (PUCRS), em Porto Alegre, RS, Brasil. autor(es) antes da publicação 